\title{
Two Dimensional Gel Electrophoresis
}

National Cancer Institute

\section{Source}

National Cancer Institute. Two Dimensional Gel Electrophoresis. NCI Thesaurus. Code C16538.

A laboratory procedure in which proteins are first separated across a gel, usually polyacrylamide, according to their isoelectric point, and then separated in a perpendicular direction on the basis of their molecular weight. 